\title{
Understanding drivers, barriers and information sources for public participation in marine citizen science
}

\author{
Victoria Y. Martin, Leslie Christidis, David J. Lloyd and Gretta T. Pecl
}

\begin{abstract}
Interviews were conducted with 110 marine users to elicit their salient beliefs about recording marine species in a citizen science project. The results showed that many interviewees believe participation would increase knowledge (either scientific, the community's, or their own). While almost half of the interviewees saw no negative outcomes, a small number expressed concerns about targeting of marine species by others, or restrictions on public access to marine sites. Most of the people surveyed $(n=106)$ emphasised the importance of well-designed technological interfaces to assist their data collection, without which they would be unlikely to engage in the project.
\end{abstract}

Keywords

Citizen science; Environmental communication; Public engagement with science and technology; Public perception of science and technology

Research on environmental issues such as climate change and genetically modified foods has provided plenty of material for scholarly discussion about the most effective ways to publicly communicate the science behind these topics, and the reasons why the public may or may not accept this information [see for example, Finucane and Holup, 2005; White and Wall, 2008]. Another area of global interest is the health and state of our marine environment and the ecological changes being detected and predicted for the future [Brierley and Kingsford, 2009; Brown et al., 2010; Halpern et al., 2008; Hobday and Pecl, 2014; McCauley et al., 2015]. No matter how far we live from the coastline, the ocean dictates our climate, accounts for a large share of our food supply, and plays an important role in the economic prosperity of many nations [Kaiser et al., 2011; OPSAG, 2013]. Yet our knowledge about this valuable environment is relatively limited; it is said we know more about space than we do about life in our oceans [Copley, 2014; NOAA, 2013]. There is clearly an urgent need to increase our understanding of the oceans at a greater rate. Public participation in marine research has enormous potential to contribute substantially to data collection effort, given the considerable number of people who use the ocean for recreational or commercial purposes.

There is also growing recognition of the need for more meaningful public engagement with scientific research and the knowledge it contributes to the way humans use, manage and protect natural ecosystems such as the marine 
environment [Chilvers et al., 2014; DIISRTE, 2012; Ressurreição et al., 2012]. Scholars studying the relationship between science and society talk of the 'participatory turn' in acknowledgement that the public can, and should, make important contributions to scientific knowledge [Burgess, 2014; Jasanoff, 2003; Jasanoff, 2014; Lengwiler, 2008]. Increased interest in public science engagement has helped drive a recent surge in the 'citizen science' movement, in which the lay public (citizens) facilitate scientific processes in some way [Bonney et al., 2009; Crall et al., 2010; Roy et al., 2012].

Reflecting a global trend, the number of marine citizen science projects in Australia has dramatically increased in recent years [Sbrocchi, 2014] and continues to do so. The public can now become involved in a wide range of marine research, such as recording out-of-range species [Robinson et al., 2015], collecting observational data on marine species [Beeden et al., 2014] and monitoring marine debris [Smith and Edgar, 2014]. Internet searches and an analysis by Sbrocchi [2014] reveal the number of Australian marine citizen science projects appears to be at least several dozen (and growing), with most having a local or regional focus and only a small handful operating at a national or global level.

One marine citizen science project with a national focus is Redmap (Range Extension Database and Mapping project, www.redmap.org.au), which is hosted nationally by the Institute for Marine and Antarctic Studies at the University of Tasmania. Redmap invites Australian marine users to report sightings of marine species that are uncommon to a particular area i.e. species that may be 'range-shifting' in response to environmental change [Robinson et al., 2015]. The national focus of Redmap provides a useful case study to examine public responses to marine citizen science.

With the amount of interest, effort and resources going into marine citizen science, it is timely to ask: what are the key drivers and barriers for public participation? The challenge for scientific organisations and scientists is to design citizen science projects to engage lay people in research effectively, yet few have paused to consult the public about their interests in citizen science. Nisbet and Scheufele [2009] emphasise the importance of understanding the audience's perspectives and communication preferences for more effective engagement in science. Audience research will enable a more strategic direction for citizen science, and ensure that projects are designed for, and target, the interests of the community for maximum uptake and engagement.

The aim of this paper is to report on the breadth of issues about drivers and barriers for public participation in marine citizen science. For the purposes of this research, the marine environment encompasses oceans, coastal beaches, and estuaries. The results presented here are the first stage of a social psychological investigation into Australian marine users to uncover the most relevant factors influencing their involvement in marine research. This stage involves eliciting the key issues for the study group (marine users) from a sub-sample, to develop pertinent questions for a subsequent survey of the larger population of marine users. We also report here the preferred media and information sources - an important consideration in gaining the attention of the audience in the first place. The findings are discussed in light of the formative purpose of the interviews, and future research directions are suggested. 
The key target audiences were defined through an analysis of the characteristics of the audience currently engaged with the Redmap project. Three groups emerged from this analysis. Two priority groups, SCUBA divers and fishers, were identified as the most frequent contributors to data collection efforts. The third group encompassed all 'other' marine uses (such as beach walking, boating and sailing, etc.).

While activity type was the primary focus for targeting respondents, potential for regional differences also existed (such as seasonal effects on participation rates and acceptance of prevailing marine estate management regimes). In addition, latitudinal differences exist in climate change effects on marine ecosystems [Poloczanska et al., 2007]. For example, temperate southern regions are experiencing much greater rates of ocean warming than the tropical north of Australia [Hobday and Pecl, 2014]. As a consequence, the public in these areas may be more aware of the changes not only through their own observations, but also through increased media attention to these issues.

Since the aim was to gather a broad range of beliefs about participation in marine research, and that these beliefs may vary between regions, the decision was made to interview respondents in four key areas across Australia. These were the towns of Brunswick Heads, Byron Bay and Ballina in northern New South Wales (herein called the NSW sample), Townsville in Far North region of Queensland (herein called the QLD sample), Hobart and surrounds in Tasmania (herein called the TAS sample), and Perth and Busselton in Western Australia (herein called the WA sample).

\section{Sampling instrument}

A face-to-face structured interview [Bryman, 2012] was developed to ask questions around the following themes:

- use of the marine environment (activities, frequency, preferences etc.);

- beliefs about participating in a sightings-based marine citizen science project;

- current, preferred and trusted information sources;

- demographics.

\section{Measure development}

Marine use questions were developed to determine participation rates in marine activities, location and frequency. An additional question asked interviewees: Of all the activities you do in the marine environment, which one is the most important to you? This question was used to identify which activity group the respondent would most identify with, and was used as the key grouping variable in the data analysis.

Questions on beliefs about participation in marine citizen science were developed using the Reasoned Action Approach/Theory of Planned Behaviour (RAA/TPB) elicitation methodology [Ajzen, 1991; Fishbein and Ajzen, 2010]. 
This approach is useful in helping understand the factors which influence behaviour. In this case, the behaviour is reporting sightings to a marine citizen science project. During the interviews respondents were presented with a hypothetical project modelled on Redmap. According to Fishbein and Ajzen [2010], a hypothetical situation can be a valid approach to understanding behaviour.

Using the RAA/TPB framework, open-ended questions were asked concerning the respondent's beliefs about the behaviour (participating in the marine citizen science project by reporting sightings of marine species), injunctive and descriptive social norms and control. Behavioural beliefs are beliefs a person has about the outcomes (the advantages or disadvantages) of a particular behaviour. Injunctive norms are, in essence, the pressure a person feels from others who are important to them to perform the particular behaviour (in this case, it means the ability of others to influence whether you would report a sighting or not). Descriptive norms reflect the perception that others are behaving a certain way, whether they are or not (in this case, it is the perception that important people in your life are reporting sightings, or not). Control beliefs are beliefs about the degree to which a person can actually perform the behaviour, and the strength of their control over performing the behaviour (which in this case includes beliefs about factors which may help or prevent them from reporting sightings of marine species).

Interviewee's information sources were asked about in four different ways. First, respondents were asked on which online platforms (web sites, forums etc.) they see images of marine species posted by other marine users. This was to determine the popular methods for spreading information about sightings of marine species outside of a scientific context. Second, respondents were also asked where they currently receive 'correct' information about the marine environment. The term 'correct' was used to imply perceived truthfulness in the information, rather than strictly scientifically accurate information. This distinction is important to understand who and what sources of information are considered by marine users to be truthful or accurate. The third question asked them for their preferred way to receive correct information about the marine environment; while the fourth question asked which sources they trust the most for correct information. The list of possible sources were drawn up from information gained in recent Australian public opinion polls on science and technology [DBI, 2012; Searle, 2014] and an 'other' category was provided to capture any additional sources.

The majority of demographic questions were taken directly from the latest national census conducted in 2011 (retrieved from http:/ / www.abs.gov.au). The questions used in the interviews are presented in the supplementary material.

\section{Pilot testing and clarification of questions}

Once the survey instrument was developed, it was pilot tested on 12 people who were known to the lead researcher to be involved in a variety of marine activities. Some minor adjustments to wording of the questions were made at this point, and the survey was sent to Liam Smith, Director of BehaviourWorks (a team of behaviour change researchers, based at Monash University) for comment. Following this, further minor changes were made to the order and wording of some questions. 
Table 1. Preferred activity group and gender.

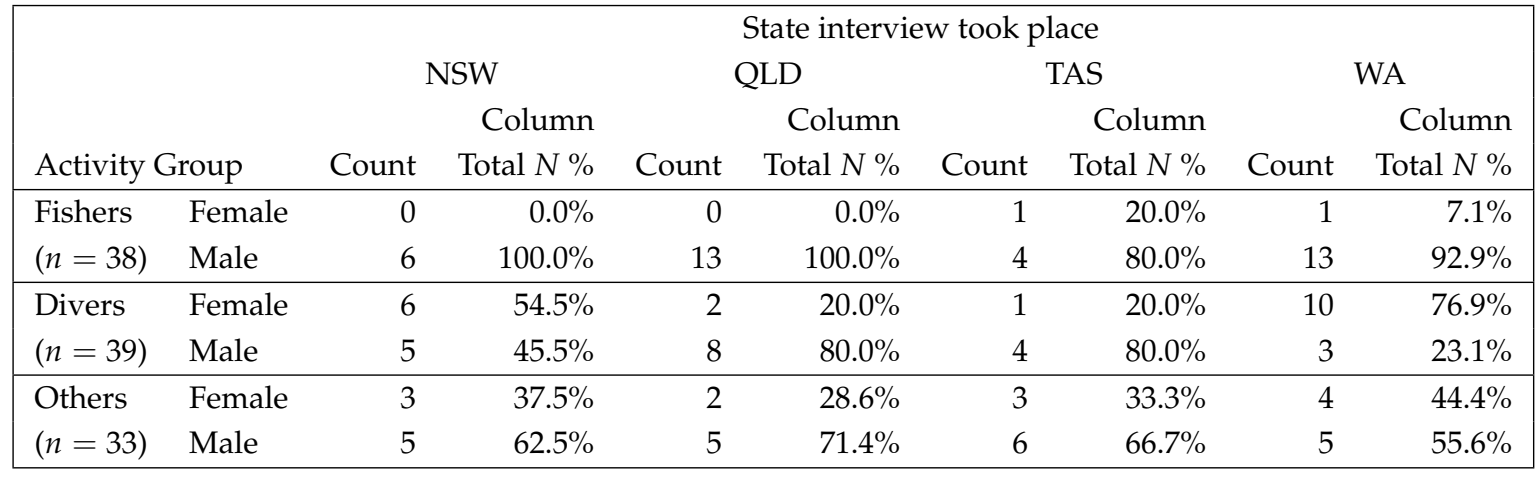

\section{Sampling procedures}

Number of interviewees. A minimum number of 25 respondents in each target group (fishers, divers and other marine users) were required to run statistical analysis on differences between the groups [Fishbein and Ajzen, 2010]. The sampling matrix achieved can be seen in Table 1. While the majority of respondents were unaware of the Redmap project prior to the interview, 12 people who had previously logged sightings in Redmap were also interviewed to determine whether there were any different issues for this group. Of these, eight were in the Western Australian sample and four were in the Tasmanian sample.

Sampling approach. All interviews took place between May - August 2014. The stratified random sampling approach [Bryman, 2012] worked well for reaching $60 \%$ of the respondents directly. Respondents were identified according to their observed activity in the marine environment. This involved approaching people at fishing locations, boat ramps and through marine-related businesses (e.g. customers or staff in shops or clubs). Care was taken to talk to a wide range of ages, interests (e.g. people who fish occasionally from shore through to people who are heavily involved in professional or game fishing) and locations around the region. The additional $40 \%$ of respondents were gained through snowball sampling [Bryman, 2012]. This method was especially necessary for most of the diver interviews as it was difficult to access divers during the winter months of the sampling period.

\section{Analysis}

Use of the marine environment, information sources, and demographics. Simple frequencies and percentages were used to gain an overall picture of the types of activities, use of the marine environment, information sources and demographics of the sample group.

Beliefs about participation in marine citizen science. In this first stage of the application of the RAA/TPB, the researcher is concerned more about eliciting the range of beliefs from the sample population rather than being able to draw conclusions about the importance of each belief uncovered in the interview process [Fishbein and Ajzen, 2010]. 
The behavioural, normative and control beliefs elicited during the interviews were subjected to a content analysis to draw out the salient themes [Fishbein and Ajzen, 2010]. To strengthen the reliability of the results, three researchers independently coded the open-ended responses to these questions [Bryman, 2012; Krippendorff, 2004b]. An inter-coder reliability test was performed using Krippendorff's alpha $\alpha$ [Krippendorff, 2004a], and confidence was determined by a bootstrapping routine using 10,000 samples. The results of each reliability test are presented at the end of each table of beliefs about participation.

Some caution may need to be applied in the interpretation of the results for the advantages of logging (i.e. reporting sightings) question as this was the only variable in the inter-coder reliability test which scored $\alpha<0.8000$. Further investigation of the coding revealed that one coder consistently coded this variable differently to the other coders. Time and funding restrictions meant that retraining and recoding were not possible, so the decision was made to drop this coder from the analysis for this variable only. When the reliability test was run on the two remaining coders, agreement between coders was found to be within acceptable limits $(\alpha=0.8254)$.

Demographics. The sample of respondents varied widely in their age (15-74 years) and tertiary qualifications (43.6\% had university-level qualifications). There were more males $(n=77)$ than females $(n=33)$, and female fishers were particularly difficult to locate (Table 1 ).

Use of the marine environment. The reported activities were wide-ranging; with beach walking/beach combing being the most frequently mentioned activity in NSW $(64.0 \%)$, TAS (73.7\%) and WA (66.7\%). The most popular activity in QLD was recreational fishing $(83.3 \%)$. After beach walking, popular activities included fishing, snorkelling, SCUBA diving and swimming. The high popularity of fishing and diving is no surprise in this result, as fishers and divers were specifically targeted for the interviews.

Most respondents were very active in the marine environment, with the majority (63-76\%) using it at least once a week in all states except Queensland where $43.3 \%$ visit at least once a week, and $43.3 \%$ visit at least once a month.

\section{Beliefs about participation}

Perceived advantages and disadvantages of reporting sightings. When asked what they saw as the advantages of logging (reporting) sightings of uncommon species, the majority of responses referred to increasing knowledge (Table 2). Many interviewees thought that it would increase scientific knowledge, provide information for the 'greater good', or increase their own knowledge. Raising public awareness about the marine environment was also seen to be a positive outcome, as was the protection or management of the ocean.

Almost half of the interviewees thought that there would be no disadvantages resulting from logging uncommon marine species (Table 2). The remaining half 
Table 2. Perceived advantages and disadvantages of reporting sightings.

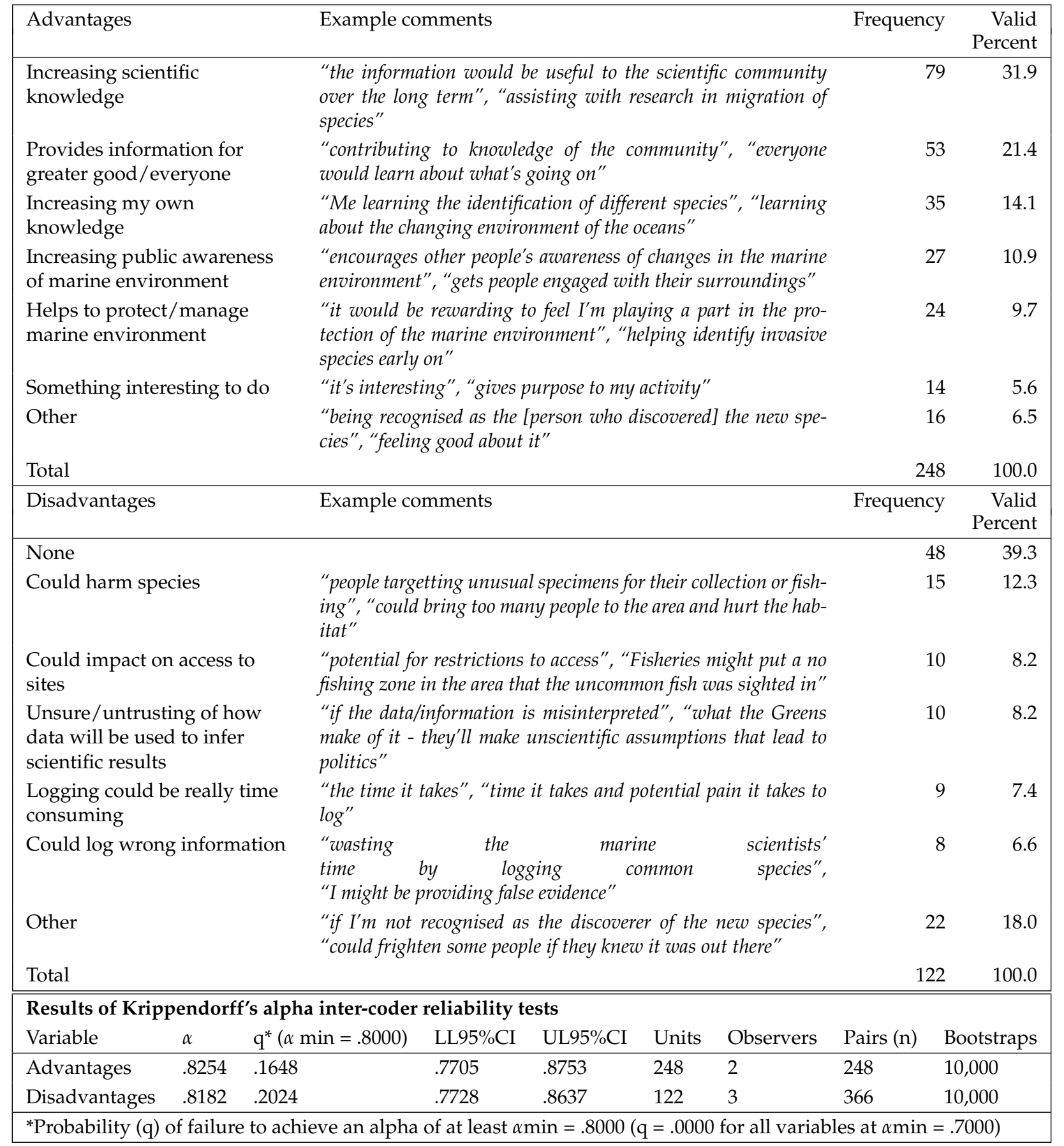

most often named only one or two disadvantages. Some were concerned about the impact on species should information on their location be made public, thereby resulting in species being targeted by poachers or collectors. A few respondents were concerned about the provision of information resulting in restrictions to their access to marine areas should the species or location be identified as needing protection. Several people also thought that the information provided by the public may not be all that useful from a scientific perspective. A few people also thought that logging sightings could be really time consuming or were concerned that they might log incorrect information and therefore waste scientists' time. 
Table 3. Perceived social norms of reporting sightings (injunctive and descriptive).

\begin{tabular}{|c|c|c|c|c|c|c|c|c|}
\hline \multicolumn{7}{|c|}{ Who approves (injunctive norm) } & Frequency & $\begin{array}{r}\text { Valid } \\
\text { Percent }\end{array}$ \\
\hline \multicolumn{7}{|l|}{ Family } & 88 & 28.2 \\
\hline \multicolumn{7}{|l|}{ Friends } & 80 & 25.6 \\
\hline \multicolumn{7}{|c|}{ Colleagues (e.g. boss/workmates) } & 43 & 13.8 \\
\hline \multicolumn{7}{|c|}{ Recreational peers e.g. other divers/fishers } & 31 & 9.9 \\
\hline \multicolumn{7}{|l|}{ Club members } & 25 & 8.0 \\
\hline \multicolumn{7}{|l|}{ Other } & 45 & 14.4 \\
\hline \multicolumn{7}{|l|}{ Total } & 312 & 100.0 \\
\hline \multicolumn{7}{|c|}{ Who disapproves (injunctive norm) } & Frequency & $\begin{array}{r}\text { Valid } \\
\text { Percent }\end{array}$ \\
\hline \multicolumn{7}{|l|}{ None } & 95 & 82.6 \\
\hline \multicolumn{7}{|l|}{ Certain fishers } & 10 & 8.7 \\
\hline \multicolumn{7}{|l|}{ Family/friends } & 6 & 5.2 \\
\hline \multicolumn{7}{|l|}{ Other } & 4 & 3.5 \\
\hline \multicolumn{7}{|l|}{ Total } & 115 & 100.0 \\
\hline \multicolumn{9}{|c|}{ Results of Krippendorff's alpha inter-coder reliability tests } \\
\hline Variable & $\alpha$ & $\mathrm{q}^{*}(\alpha \min =.8000)$ & LL95\%CI & UL95\%CI & Units & Observers & Pairs (n) & Bootstraps \\
\hline \multirow{2}{*}{$\begin{array}{l}\text { Who approves } \\
\text { Who disapproves }\end{array}$} & .9316 & .0000 & .9103 & .9525 & 312 & 3 & 936 & 10,000 \\
\hline & .9043 & .0032 & .8284 & .9604 & 115 & 3 & 345 & 10,000 \\
\hline
\end{tabular}

\section{Perceived social norms (injunctive and descriptive)}

Respondents mentioned a range of people who may or may not influence their logging behaviour (Table 3). People who would approve, or encourage, the interviewee to log a sighting (the positive injunctive norm) were thought to be primarily family and friends. While a clear majority of respondents (95 of the 110 interviewees) said there were no important people in their lives who would discourage (or disapprove of) them from logging a sighting (the negative injunctive norm), some fishers mentioned that certain other fishers in their social circles might discourage them from reporting uncommon species.

There was some confusion over the question of descriptive norms, and it became clear that although interviewees could identify others types of marine users who may be likely or unlikely to log sightings, it is not a commonly observed behaviour amongst marine users and therefore there are effectively no important people in the marine users' social networks who are demonstrating the desired behaviour. Therefore, the descriptive norms are irrelevant to this audience and this construct has been removed from the analysis.

\section{Perceived facilitating factors and barriers to participation}

Interviewees reported factors which would facilitate them to report sightings of uncommon marine species, as well as perceived barriers to logging (Table 4). The overwhelming majority of facilitating factors listed were to do with the design of the technological interface, that is, the website or mobile app. People said that it needed to be easy, user-friendly and quick to use, and have no problems or glitches in the system. Twelve percent of the comments were about information to help 
Table 4. Facilitating and inhibiting factors influencing the reporting of sightings.

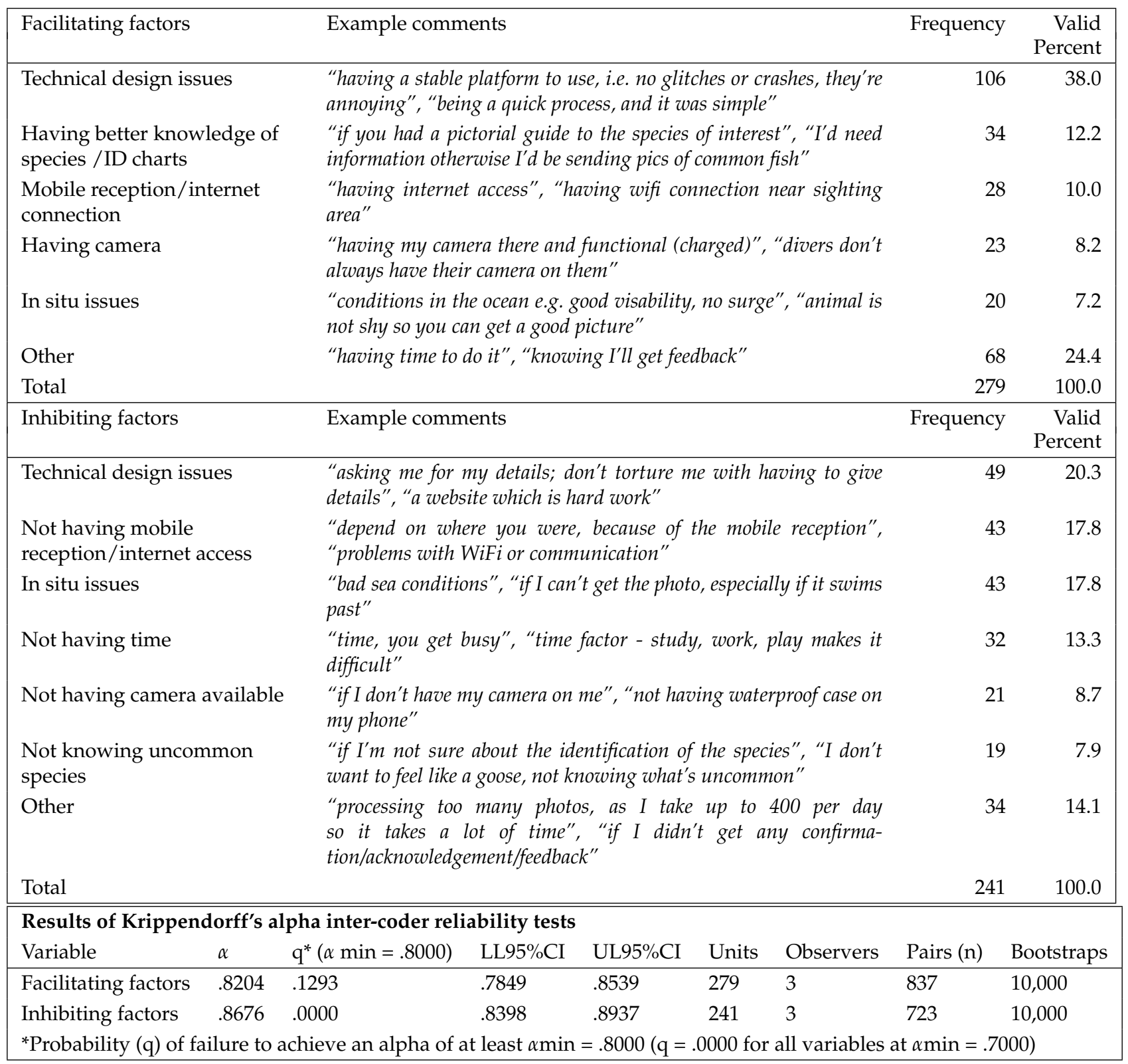

them work out whether a species was uncommon or not. Some interviewees also mentioned that mobile reception or internet connection at the time of the sighting would be necessary (it had not been explained to them that they could log sightings when they were back in mobile range). Having a camera available at the time of the sighting was seen to be an issue for some, especially since many do not take their cameras with them whilst diving or participating in other water-related activities. Other comments related to in situ issues such as having good weather, or good visibility (either under or above the water), to see the species in the first place.

Inhibiting factors, or barriers, are those which would make it difficult or prevent the person from logging a sighting. The results from this question are largely the reverse of the facilitating factors. That is, the most frequently mentioned potential barriers were considered to be the technical design (if the web site or mobile app is too difficult, time consuming etc), the availability of the internet connection, and in 
situ issues (such as weather). One exception is 'having time', which was reported by 32 respondents, meaning that these people felt the general 'busy-ness of life' could prevent them from logging a sighting. Interestingly, fewer people considered their knowledge of marine species to be a barrier than those who reported 'having better knowledge of species/ID charts' as a facilitating factor.

\section{Information sources}

The results from the questions about currently used and preferred information sources show interesting differences between preferences and actual use (Table 5). While the majority $(75.5 \%)$ of marine users appeared well connected via Facebook (reporting this is where they most often see others' images of marine species online), only $35.5 \%$ currently used Facebook as a source of 'correct' information about the marine environment. The internet featured as the most frequently mentioned $(76.4 \%)$ source of correct information, while around half of the interviewees mentioned government agencies, friends and family, and television programs. The results of the most preferred method to receive correct information about the marine environment showed disparate responses. The most popular preference was for information on the internet $(40.0 \%)$, followed by face-to-face interactions with others (14.5\%). A little over half (52.8\%) of the respondents listed government agencies, scientists or scientific organisations as their most trusted source of correct information.

The results from the present study demonstrate the potential, as seen through the eyes of the public, for their participation in marine research to make genuine contributions to knowledge for science and society at large. The interview responses also strongly emphasise the importance of well-designed web sites and mobile apps for those who are voluntarily contributing data. When it comes to communicating information about the marine environment, this research also reminds us that although the internet now plays a key role in communication, face-to-face communication remains important to marine users.

The interviewees in this study, although relatively small in number, covered a broad range of interests in the marine environment. The larger number of males in the sample is not surprising given that other studies have also reported higher participation rates in marine activities for males than females [Australian Bureau of Statistics, 2012; Henry and Lyle, 2003]. The majority of respondents were highly active in the marine environment, and it is likely that their frequent use of the ocean may have made it easier to identify them in the sampling process. As a result, the sample is likely to under-represent people who are less active in marine settings, but for whom the oceans and beaches are no less important. Whether or not these people are interested in participating in marine citizen science is another question.

\section{Beliefs about participation in marine citizen science}

When asked about outcomes from logging uncommon marine species, many interviewees listed altruistic motivations. That is, many thought the main advantage was to increase knowledge for science or for the greater good. This 


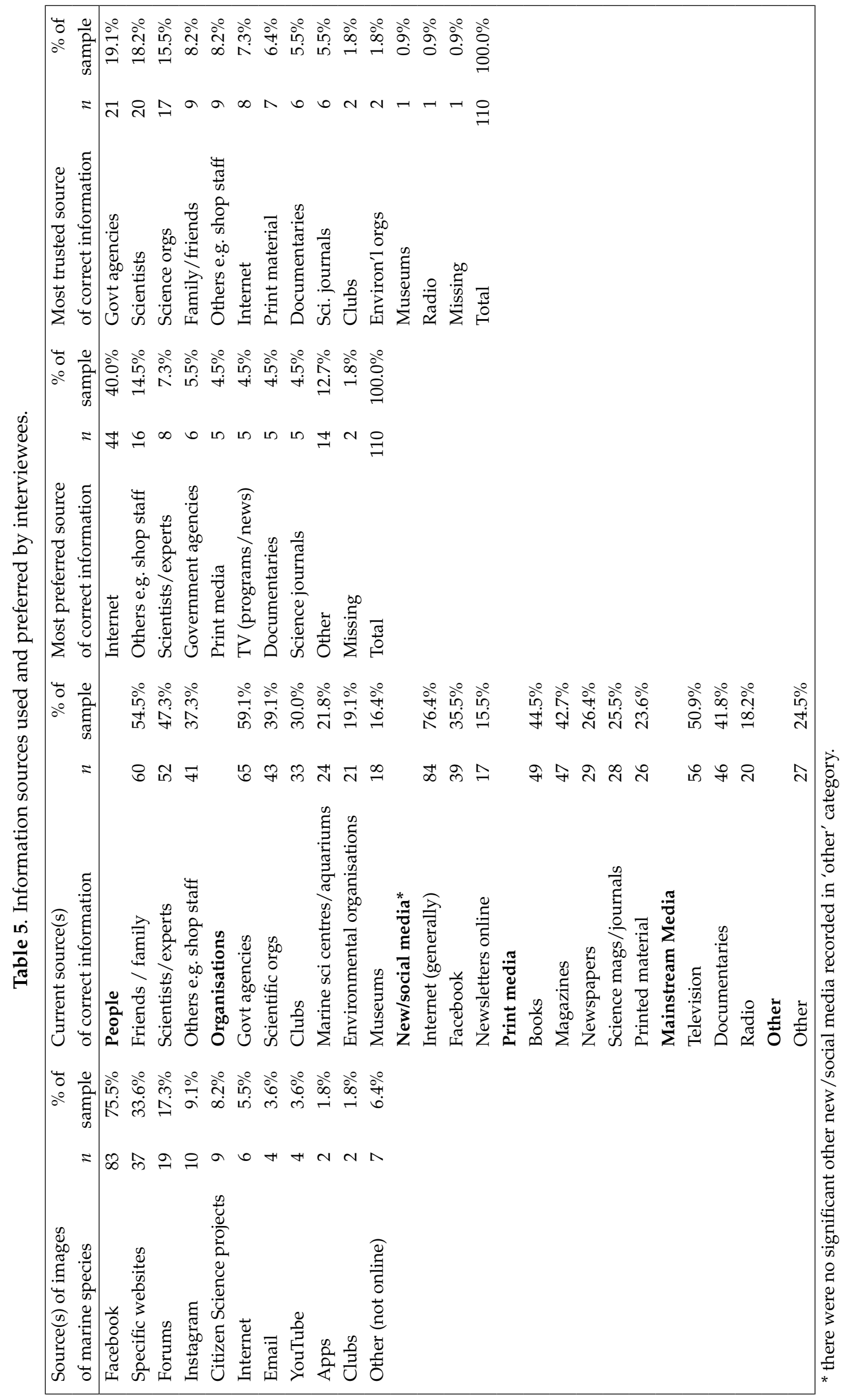


finding is similar to that of a survey of people already participating in citizen science, albeit an online astronomy project [Raddick et al., 2013]. These findings bring up another question: why do they see this as a good outcome or advantage of their contribution? Perhaps it is linked with the high level of public interest in science and technology information in Australia [DBI, 2012; Lamberts, Grant and Martin, 2010; Searle, 2014]. The ability to increase one's own knowledge was also seen to be an advantage, and interviewees' passion for the marine environment was evident in their thoughts that their contribution would help raise awareness and help manage or protect this resource. The inclusion of these perceived outcomes may be beneficial in future communication strategies for increasing public engagement in projects.

Reporting sightings was generally seen as a good thing to do, with almost half of the respondents saying they did not perceive there to be disadvantages to logging uncommon species. A few people were worried about the potential for the information to be used to target species for poaching or collection, or to restrict access through the implementation of marine protected areas (MPAs). MPAs have become a contentious subject, particularly for recreational fishers, in several regions across Australia [Gledhill et al., 2014; Voyer, Gladstone and Goodall, 2014] and could possibly present a very real barrier for contribution of sightings from some fishers. This is an important consideration for marine citizen science projects, many of which aim to make the information they collect publicly available for the benefit of all.

Additionally, some respondents thought publically-collected data would not be robust enough to make scientifically sound decisions about changes in the marine environment. The interviewer noted that this attitude was largely held by those with a background in science. Riesch and Potter [2014] found that this attitude toward citizen science is relatively common amongst scientists, despite evidence to the contrary showing that public data collection can be a valuable and sometimes necessary tool for improving understanding of natural environments [Azzurro et al., 2013; Devictor, Whittaker and Beltrame, 2010; Dickinson et al., 2012; Jarvis et al., 2015; Robinson et al., 2015].

An important element of project design which managers should be mindful of is the technological aspect. Marine users said they would need a simple, quick, user-friendly website or mobile app which was free from glitches. Should technological problems be encountered, many interviewees felt they would discontinue with the project. This presents a significant challenge for many marine citizen science projects which are often operating with low levels of funding, and sometimes a lack of technological expertise.

Other facilitating factors included the provision of information about marine species under investigation, and highlighting the importance of clarity of what the contributor is being requested to do for the project. By providing more information, not only is the citizen scientist more certain about what is required, but the project will be providing an opportunity for people to learn more, which was seen as an important reason for citizens to participate. 
Inhibiting factors, or barriers, were largely the reverse of the perceived facilitating factors. The marine users were most concerned about the technical aspects of the project website or mobile app, once again highlighting the importance that systems operate easily for the end user. Some of the interviewee's concerns were to do with issues beyond the control of a citizen science manager (e.g. lack of internet connection (especially for mobile apps), in situ conditions such as the weather, or not having time to participate). In a practical sense, internet connection should not be an issue for people since most citizen science mobile apps are designed to store sighting records and send them once internet connection is established. However, what is important here is the interviewees' perception that a sighting would have to be logged at the exact time and location of the event. This is not the case in Redmap, or other similar projects, but is something which citizen science projects should be mindful of in their recruitment communication. Although most Australians have convenient access to the internet [Internet World Stats, 2012], marine users who prefer to log sightings through a website may encounter unstable internet connection (particularly in regional and remote locations). If connectivity issues become too frustrating, people are unlikely to continue in their attempts to record species. While there is nothing a manager can do about this, or other perceived barriers (such as in situ or time pressures), they are nevertheless important to consider in the project design. Clearly, should these barriers present too much of a problem for people, the project will struggle to succeed.

Social norms (i.e. the influence of others) offer the possibility to generate more interest in citizen science participation; and in a marine setting, family and friends could be particularly influential. Communication strategies utilising these connections, such as encouraging the sharing of the project information via social media platforms such as Facebook, may prove to be a fruitful approach in a low-budget citizen science operation. While seeing other recreational peers logging sightings was rare, project communicators should consider showcasing the latest sightings. Research by Mugar, Osterlund, DeVries Hassman, Crowston, and Jackson [2014] demonstrates that new users can be drawn into participating in a citizen science project through seeing others' contributions to the project, thereby understanding the norms of practice within the group.

\section{Information sources}

Understanding the information sources used and preferred by the target audience for any communication of science is essential for successful engagement [Fischhoff, 2013]. The differences in responses to four different questions about information sources emphasise the importance of asking the right question in the first place. Most of the marine users in this study showed a high level of sharing marine species information on Facebook in a non-scientific context. Yet in their reporting of current sources of 'correct information' about the marine environment, Facebook was mentioned by only half of these people. This means that while Facebook may have an important role in spreading information, particularly through the social influence of family and friends, it should be used with some caution about the perceived accuracy of the information.

Government agencies, scientists and scientific organisations play an essential role as preferred and trusted sources of information, which comes as no surprise given 
the high level of trust Australians place in the information provided by scientists and scientific organisations [Searle, 2014]. However, it is important to note that although government agencies, scientists and scientific organisations were cited most frequently, only half of the respondents listed these as their most trusted source. The other half put their trust in a much wider pool of information providers, highlighting the importance of understanding trust issues for any particular audience.

\section{Future research}

This study investigates only one element of public involvement in marine science, that is, the perceived drivers and barriers for participation. These insights are necessary for the development questions which are relevant to the broader target audience in future research. It also allows for the wording of questions to be in the vernacular of the target audience; an important element in the creation of useful and successful survey questions [Cialdini, 2003; Greenhill et al., 2014].

The next step in the application of the RAA/TPB (Fishbein \& Ajzen, 2010) is to determine how important these drivers and barriers are to the wider target audience. When we understand this, we can adopt the course of action most likely to improve the degree and quality of public engagement through relevant messages and considered project design [Shirk et al., 2012].

If we are to determine the potential for marine citizen science to improve the public's relationship with science, we will also need to ask how many people are interested in participating in the first place, and which aspects of projects they would prefer to engage with (such as data collection, analysing results and so on). We will also need to understand differences between those who are interested in assisting citizen science, and those who are not [Cormick, 2014]. At this point in time, we are uncertain whether citizen science is likely to attract those who are currently unengaged or uninterested in science, or whether it is simply 'preaching to the converted'. In addition there are, of course, even more factors at play that help to explain public science engagement and it is encouraging to see social research being conducted around the globe on these matters [see, for example, Feist, 2012; Kazdin, 2009; Markowitz et al., 2013; Oppenheimer and Todorov, 2006; Stern, 2011].

Acknowledgments The authors would like to convey their gratitude for assistance from the Redmap Australia project team (www.redmap.org.au, hosted nationally by IMAS at the University of Tasmania), Nadine Marshall (CSIRO Ecosystem Sciences) and the School of Environment, Science \& Engineering, Southern Cross University. VM was supported by an Australian Postgraduate Award. GP was supported by an ARC Future Fellowship.

Funding

This research received no specific grant from any funding agency in the public, commercial, or not-for-profit sectors. 
Ajzen, I. (1991). 'The theory of planned behavior'. Organizational Behavior and Human Decision Processes 50 (2), pp. 179-211. DOI: 10.1016/0749-5978(91)90020-T.

Australian Bureau of Statistics (2012). Participation in Sport and Physical Activities, Australia, 2011-2012 (cat. no. 4177.0). Canberra, Australia: ABS.

Azzurro, E., Broglio, E., Maynou, F. and Bariche, M. (2013). 'Citizen science detects the undetected: the case of Abudefduf saxatilis from the Mediterranean Sea'. Management of Biological Invasions 4 (2), pp. 167-170. DOI: 10.3391/mbi.2013.4.2.10.

Beeden, R. J., Turner, M. A., Dryden, J., Merida, F., Goudkamp, K., Malone, C., Marshall, P. A., Birtles, A. and Maynard, J. A. (2014). 'Rapid survey protocol that provides dynamic information on reef condition to managers of the Great Barrier Reef'. Environmental Monitoring and Assessment 186 (12), pp. 8527-8540. DOI: $10.1007 / \mathrm{s} 10661-014-4022-0$.

Bonney, R., Cooper, C. B., Dickinson, J., Kelling, S., Phillips, T., Rosenberg, K. V. and Shirk, J. (2009). 'Citizen Science: A Developing Tool for Expanding Science Knowledge and Scientific Literacy'. BioScience 59 (11), pp. 977-984. DOI: 10.1525/bio.2009.59.11.9.

Brierley, A. S. and Kingsford, M. J. (2009). 'Impacts of Climate Change on Marine Organisms and Ecosystems'. Current Biology 19 (14), R602-R614. DOI: 10.1016/j.cub.2009.05.046.

Brown, C. J., Fulton, E. A., Hobday, A. J., Matear, R. J., Possingham, H. P., Bulman, C., Christensen, V., Forrest, R. E., Gehrke, P. C., Gribble, N. A., Griffiths, S. P., Lozano-Montes, H., Martin, J. M., Metcalf, S., Okey, T. A., Watson, R. and Richardson, A. J. (2010). 'Effects of climate-driven primary production change on marine food webs: implications for fisheries and conservation'. Global Change Biology 16 (4), pp. 1194-1212. DOI: $10.1111 / \mathrm{j} .1365-2486.2009 .02046 . x$.

Bryman, A. (2012). Social research methods. 4th ed. Oxford, U.K.: Oxford University Press.

Burgess, M. M. (2014). 'From 'trust us' to participatory governance: Deliberative publics and science policy'. Public Understanding of Science 23 (1), pp. 48-52. DOI: 10.1177/0963662512472160.

Chilvers, J., Lorenzoni, I., Terry, G., Buckley, P., Pinnegar, J. K. and Gelcich, S. (2014). 'Public engagement with marine climate change issues: (Re)framings, understandings and responses'. Global Environmental Change 29, pp. 165-179. DOI: $10.1016 / \mathrm{j}$. gloenvcha.2014.09.006.

Cialdini, R. B. (2003). 'Crafting Normative Messages to Protect the Environment'. Current Directions in Psychological Science 12 (4), pp. 105-109. DOI: 10.1111/1467-8721.01242.

Copley, J. (9th October 2014). 'Just How Little Do We Know about the Ocean Floor?' The Conversation. URL: https://theconversation.com/just-how-little-do-w e-know-about-the-ocean-floor-32751.

Cormick, C. (2014). Community Attitudes towards Science and Technology in Australia. Canberra, Australia: CSIRO.

Crall, A. W., Newman, G. J., Jarnevich, C. S., Stohlgren, T. J., Waller, D. M. and Graham, J. (2010). 'Improving and integrating data on invasive species collected by citizen scientists'. Biological Invasions 12 (10), pp. 3419-3428. DOI: 10.1007/s10530-010-9740-9. 
DBI (2012). Community interest and engagement with science and technology in Victoria 2011. Melbourne, Australia: Department of Business and Innovation, Government of Victoria.

Devictor, V., Whittaker, R. J. and Beltrame, C. (2010). 'Beyond scarcity: citizen science programmes as useful tools for conservation biogeography'. Diversity and Distributions 16 (3), pp. 354-362. DOI: 10.1111/j.1472-4642.2009.00615.x.

Dickinson, J. L., Shirk, J., Bonter, D., Bonney, R., Crain, R. L., Martin, J., Phillips, T. and Purcell, K. (2012). 'The current state of citizen science as a tool for ecological research and public engagement'. Frontiers in Ecology and the Environment 10 (6), pp. 291-297. DOI: 10.1890/110236.

DIISRTE (2012). Marine science: a story for Australia. URL: http://www . industry.gov.au/science/InspiringAustralia.

Feist, G. J. (2012). 'Predicting interest in and attitudes toward science from personality and need for cognition'. Personality and Individual Differences 52 (7), pp. 771-775. DOI: 10.1016/j . paid.2012.01.005.

Finucane, M. L. and Holup, J. L. (2005). 'Psychosocial and cultural factors affecting the perceived risk of genetically modified food: an overview of the literature'. Social Science \& Medicine 60 (7), pp. 1603-1612. DOI: $10.1016 / j$. socscimed. 2004.08 .007$.

Fischhoff, B. (2013). 'The sciences of science communication'. Proceedings of the National Academy of Sciences 110 (Supplement 3), pp. 14033-14039. DOI: 10.1073/pnas. 1213273110.

Fishbein, M. and Ajzen, I. (2010). Predicting and Changing Behavior: The Reasoned Action Approach. New York, U.S.A.: Taylor \& Francis Group.

Gledhill, D. C., Hobday, A. J., Welch, D. J., Sutton, S. G., Lansdell, M. J., Koopman, M., Jeloudev, A., Smith, A. and Last, P. R. (2014). 'Collaborative approaches to accessing and utilising historical citizen science data: a case-study with spearfishers from eastern Australia'. Marine and Freshwater Research 66 (3), pp. 195-201.

Greenhill, M., Leviston, Z., Leonard, R. and Walker, I. (2014). 'Assessing climate change beliefs: Response effects of question wording and response alternatives'. Public Understanding of Science 23 (8), pp. 947-965. DOI: 10.1177/0963662513480117.

Halpern, B. S., Walbridge, S., Selkoe, K. A., Kappel, C. V., Micheli, F., D’Agrosa, C., Bruno, J. F., Casey, K. S., Ebert, C., Fox, H. E., Fujita, R., Heinemann, D., Lenihan, H. S., Madin, E. M. P., Perry, M. T., Selig, E. R., Spalding, M., Steneck, R. and Watson, R. (2008). 'A Global Map of Human Impact on Marine Ecosystems'. Science 319 (5865), pp. 948-952. DOI: 10.1126/science. 1149345.

Henry, G. W. and Lyle, J. M., eds. (2003). The National Recreational and Indigenous Fishing Survey. Canberra, Australia: Australian Government Department of Agriculture, Fisheries and Forestry.

Hobday, A. J. and Pecl, G. T. (2014). 'Identification of global marine hotspots: sentinels for change and vanguards for adaptation action'. Reviews in Fish Biology and Fisheries 24 (2), pp. 415-425. DOI: 10.1007/s11160-013-9326-6.

Internet World Stats (2012). Internet Users in Oceania estimated for 2012 Q2. URL: http://www . internetworldstats. com/stats6.htm (visited on 13th March 2013).

Jarvis, R. M., Bollard Breen, B., Krägeloh, C. U. and Billington, D. R. (2015). ‘Citizen science and the power of public participation in marine spatial planning'. Marine Policy 57, pp. 21-26. DOI: 10.1016/j .marpol.2015.03.011. 
Jasanoff, S. (2003). 'Technologies of Humility: Citizen Participation in Governing Science'. Minerva 41 (3), pp. 223-244. DOI: 10.1023/A:1025557512320.

- (2014). 'A mirror for science'. Public Understanding of Science 23 (1), pp. 21-26. DOI: $10.1177 / 0963662513505509$.

Kaiser, M. J., Attrill, M. J., Jennings, S., Thomas, D. N., Barnes, D. K. A., Brierley, A. S., Hiddink, J. G., Kaartokallio, H., Polunin, N. V. C. and Raffaelli, D. G. (2011). Marine ecology: processes, systems, and impacts. 2nd ed. Oxford, U.K.: Oxford University Press.

Kazdin, A. E. (2009). 'Psychological science's contributions to a sustainable environment: extending our reach to a grand challenge of society'. The American Psychologist 64 (5), pp. 339-356. DOI: 10.1037/a0015685.

Krippendorff, K. (2004a). Content Analysis: An Introduction to Its Methodology. 2nd ed. Thousand Oaks, CA, U.S.A.: Sage.

- (2004b). 'Reliability in content analysis: some common misconceptions and recommendations'. Human Communication Research 30 (3), pp. 411-433. DOI: 10.1111/j.1468-2958.2004.tb00738.x.

Lamberts, R., Grant, W. J. and Martin, A. (2010). Public opinion about science ANU Poll. Canberra, Australia: Australian National University.

Lengwiler, M. (2008). ‘Participatory Approaches in Science and Technology: Historical Origins and Current Practices in Critical Perspective'. Science, Technology \& Human Values 33 (2), pp. 186-200. DOI: 10.1177/0162243907311262.

Markowitz, E. M., Slovic, P., Västfjäll, D. and Hodges, S. D. (2013). ‘Compassion fade and the challenge of environmental conservation'. Judgment $\mathcal{E}$ Decision Making 8 (4), pp. 397-406.

McCauley, D. J., Pinsky, M. L., Palumbi, S. R., Estes, J. A., Joyce, F. H. and Warner, R. R. (2015). 'Marine defaunation: Animal loss in the global ocean'. Science 347 (6219), p. 1255641. DOI: 10.1126/science.1255641.

Mugar, G., Osterlund, C., DeVries Hassman, K., Crowston, K. and Jackson, C. B. (2014). Planet Hunters and Seafloor Explorers: Legitimate Peripheral Participation Through Practice Proxies in Online Citizen Science. Paper presented at the Proceedings of the $17^{\text {th }}$ ACM conference on Computer supported cooperative work \& social computing, Baltimore, Maryland, U.S.A.

National Oceanic and Atmospheric Administration (2013). How much of the ocean have we explored? To date, we have explored less than five percent of the ocean. Revised January 11, 2013. URL:

http://oceanservice.noaa.gov/facts/exploration.html (visited on 20th August 2013).

Nisbet, M. C. and Scheufele, D. A. (2009). 'What's next for science communication? Promising directions and lingering distractions'. American Journal of Botany 96 (10), pp. 1767-1778. DOI: 10.3732/ajb.0900041.

Oppenheimer, M. and Todorov, A. (2006). ‘Global Warming: The Psychology of Long Term Risk'. Climatic Change 77 (1), pp. 1-6. DOI: 10.1007/s10584-006-9086-6.

OPSAG (2013). Marine Nation 2025: Marine science to support Australia's blue economy. Canberra, Australia: Australian Government Oceans Policy Science Advisory Group.

Poloczanska, E. S., Babcock, R. C., Butler, A., Hobday, A. J., Hoegh-Guldberg, O., Kunz, T. J., Matear, R., Milton, D. A., Okey, T. A. and Richardson, A. J. (2007). 'Climate change and Australian marine life'. Oceanography and Marine Biology 45, pp. 407-478. URL: http://espace.library.uq. edu. au/view/UQ: 135005. 
Raddick, M. J., Bracey, G., Gay, P. L., Lintott, C. J., Cardamone, C., Murray, P., Schawinski, K., Szalay, A. S. and Vandenberg, J. (2013). 'Galaxy Zoo:

Motivations of Citizen Scientists'. Astronomy Education Review 12 (1), p. 010106. DOI: 10.3847 /AER2011021. arXiv: 1303.6886.

Ressurreição, A., Simas, A., Santos, R. S. and Porteiro, F. (2012). 'Resident and expert opinions on marine related issues: Implications for the ecosystem approach'. Ocean $\mathcal{E}$ Coastal Management 69, pp. 243-254. DOI: 10.1016/j. ocecoaman.2012.09.002.

Riesch, H. and Potter, C. (2014). 'Citizen science as seen by scientists: Methodological, epistemological and ethical dimensions'. Public Understanding of Science 23 (1), pp. 107-120. DOI: 10.1177/0963662513497324.

Robinson, L. M., Gledhill, D. C., Moltschaniwskyj, N. A., Hobday, A. J., Frusher, S., Barrett, N., Stuart-Smith, J. and Pecl, G. T. (2015). 'Rapid assessment of an ocean warming hotspot reveals "high" confidence in potential species' range extensions'. Global Environmental Change 31, pp. 28-37. DOI: 10.1016/j.gloenvcha. 2014.12.003.

Roy, H. E., Pocock, M. J. O., Preston, C. D., Roy, D. B., Savage, J., Tweddle, J. C. and Robinson, L. D. (2012). Understanding citizen science and environmental monitoring: final report on behalf of UK Environmental Observation Framework. p. 175. URL: http://www . ukeof .org.uk/documents/understanding-citizen-science.pdf.

Sbrocchi, C. D. (2014). 'Evaluating the usefulness of citizen science for natural resource management in marine environments'. Master of Science. Sydney, Australia: University of Technology. URL: https://opus.lib.uts . edu.au/handle/10453/24209.

Searle, S. (2014). How do Australians engage with science? Preliminary results from a national survey. Australian National Centre for the Public Awareness of Science (CPAS): The Australian National University.

Shirk, J. L., Ballard, H. L., Wilderman, C. C., Phillips, T., Wiggins, A., Jordan, R., McCallie, E., Minarchek, M., Lewenstein, B. V., Krasny, M. E. and Bonney, R. (2012). 'Public Participation in Scientific Research: a Framework for Deliberate Design'. Ecology and Society 17 (2). DOI: 10.5751/ES-04705-170229.

Smith, S. D. A. and Edgar, R. J. (2014). 'Documenting the Density of Subtidal Marine Debris across Multiple Marine and Coastal Habitats'. PLoS ONE 9 (4), pp. 1-7. DOI: 10.1371/journal . pone. 0094593.

Stern, P. C. (2011). 'Contributions of psychology to limiting climate change'. The American Psychologist 66 (4), pp. 303-314. DOI: 10.1037/a0023235.

Voyer, M., Gladstone, W. and Goodall, H. (2014). ‘Understanding marine park opposition: the relationship between social impacts, environmental knowledge and motivation to fish'. Aquatic Conservation: Marine and Freshwater Ecosystems 24 (4), pp. 441-462. DOI: 10.1002/aqc. 2363.

White, T. and Wall, R. (2008). 'National, regional and local attitudes towards climate change: identifying appropriate target audiences for communications'. Local Environment 13 (7), pp. 589-607. DOI: 10.1080/13549830802260126. 
Victoria Martin is a Ph.D. researcher in the School of Environment, Science \& Engineering, at Southern Cross University, Australia. Her Ph.D. research is investigating the connections between science and society, and the role that public participation in marine science might play in strengthening this relationship. E-mail: vicki.martin@scu.edu.au.

Leslie Christidis is Director of the National Marine Science Centre, Southern Cross University, Australia. Previously he was in the museum sector where he led the development of several major science-based exhibitions, including planetarium productions. E-mail: les.christidis@scu.edu.au.

David Lloyd is the Associate Professor of protected area management in the School of Environment, Science \& Engineering at Southern Cross University, Australia, and has a long history of working in national and marine park management. E-mail: david.lloyd@scu.edu.au.

Gretta Pecl is the Deputy Associate Dean of Research at IMAS and an ARC Future Fellow. Her research focusses on species responses and adaptation of fisheries systems to climate change, and on citizen science approaches to ecological monitoring. E-mail: Gretta.Pecl@utas.edu.au.

\section{How to cite}

Martin, V. Y., Christidis, L., Lloyd, D. J. and Pecl, G. T. (2016). 'Understanding drivers, barriers and information sources for public participation in marine citizen science'. JCOM 15 (02), A02. 